\title{
Differences in reporting somatic complaints in elderly by education level
}

Research Article

Mindaugas Stankunas ${ }^{1,2}$, Joaquim F.J. Soares ${ }^{3}$, Aurima Stankuniene ${ }^{4}$, M. Gabriella Melchiorre ${ }^{5}$, Francisco Torres-Gonzales ${ }^{6}$, Elisabeth IoannidiKapolou$^{7}$, Henrique Barros ${ }^{8}$, Jutta Lindert ${ }^{9}$

1 School of Public Health, Griffith University, Gold Coast Campus, Queensland 4222, Australia

2 Department of Health Management, Lithuanian University of Health

Sciences, A. Mickevičiaus g. 9, LT 44307, Kaunas, Lithuania

3 Department of Public Health Sciences, Institution for Health Sciences, Mid Sweden University, SE- 85170 Sundsvall, Sweden

4 Department of Pharmaceutical Technology and Social Pharmacy, Lithuanian University of Health Sciences, A. Mickevičiaus g. 9, LT 44307, Kaunas, Lithuania

5 Scientific Technological Area, Socio Economic Research Centre, Italian National Institute of Health and Science on Aging (INRCA), Via Santa Margherita, 5, 60124, Ancona, Italy

6 Centro de Investigación Biomedica en Red de Salud Mental" CIBERSAM-Granada University, Av Madrid, 11 PC:18071 Granada, Spain

7 Department of Sociology, National School of Public Health, 196 Alexandras avenue, Athens 11521, Greece

8 Department of Clinical Epidemiology, Predictive Medicine and Public Health, University of Porto; Medical School and Institute of Public Health of the University of Porto, Porto, (4200-319), Portugal

9 Department of Public Health, Protestant University of Applied Sciences, Paulusweg 6, 71638 Ludwigsburg, Germany and Department of Psychology and Sociology, University of Leipzig, Leipzig, Germany

Received 20 April 2012; Accepted 21 September 2012

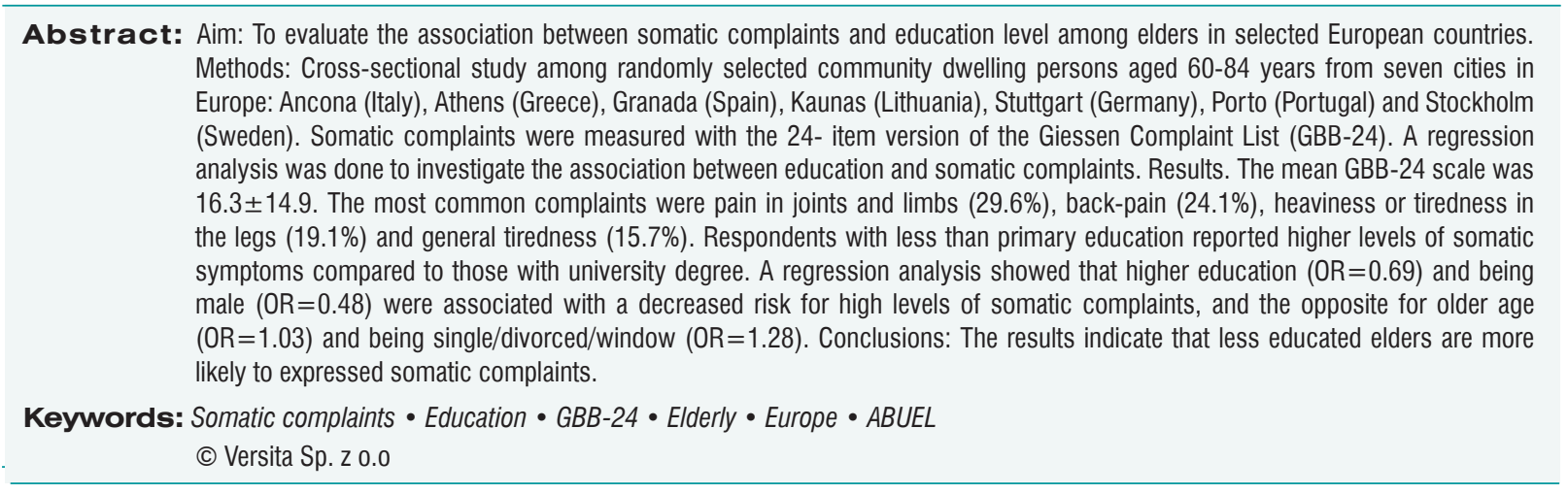

*E-mail:m.stankunas@griffith.edu.au 


\section{Introduction}

Demographic trends and increase of welfare in Europe has led to an increased number of older persons in society [1]. It is commonly agreed that the rapid aging of population will subsequently change the socio-demographic structure of society and pose challenges to the use of health care services [2]. According to the World Health Organization (WHO) major threats for this group are dementia, and somatic disorders (e.g. cancer). Therefore, the assessment of health status of this group is of growing importance.

It has been established that self-rated health $(\mathrm{SRH})$ is not only a valid and reliable indicator of the general health of the population, but also a good predictor of mortality and morbidity [3,4]. Presently, there is a growing interest in investigating subjective health complaints, which can be early manifestations of somatic diseases [5]. A growing number of studies emphasize the high correlations between socio-demographic and economic factors and subjective health complaints in older persons [6-9]. However, these studies tend to present data only from national samples and with different methodologies. This limits possibilities for making international comparisons. To the best of our knowledge, there are no international, multi-centre studies on this issue.

Thus, the aim of the paper was to evaluate the association between somatic complaints and education level among community dwelling adults aged 60-84 in seven cities from seven countries in Europe.

\section{Methods}

\subsection{Population and design}

The data for this cross-sectional study was collected in 2009 during the European project "Elder abuse: $A$ multinational prevalence survey" (ABUEL). The target population for ABUEL was persons aged 60-84 years not suffering from dementia or other cognitive impairments and living in communities in Stuttgart (Germany), Athens (Greece), Ancona (Italy), Kaunas (Lithuania), Porto (Portugal), Granada (Spain) and Stockholm (Sweden). More detailed description of sampling, data collection, differences between responders and nonresponders and study limitations are described in a separate paper [10].

\subsection{Measures}

The participants completed a standardized questionnaire with various scales and questions (e.g. somatic complaints). This study focuses on education and somatic complaints.

We used four education groups: "less than primary" (included groups "cannot read/write", "without any degree", "less than primary school"), "primary", "secondary" and "university". The group "other" was not included in the further analysis.

Somatic complaints were measured with the short version of the Giessen Complaint List (GBB-24), which consists of 24 items (graded from 0 - "not at all" to 4 - "very much") about various somatic complaints (e.g. physical weakness) [11]. The total score amounts to 96 and the items can be divided into 4 sub-scales (exhaustion, gastrointestinal, cardiovascular, and musculoskeletal). High scores correspond to high levels of somatic complaints. Cronbach's Alpha was 0.92. In this study, GBB and its subscales scores were considered as high, when they were higher than median of entire sample.

\section{Statistical analyses}

The bivariate relation between somatic complaints and education level was analyzed with Kruskall-Wallis test. Continuous variables were presented as a mean and median together with mean's 95\% confidence intervals. Categorical variables were processed by means of Chi-square tests $\left(x^{2}\right)$.For evaluation of the impact of explanatory variables on the analyzed event (binary dependent variable), a enter model of logistic regression was used. The dependent variable was high level of somatic complaints and the independent variables were sex, age-group, marital status and education. The association between education and somatic complaints was measured computing odds ratio (OR) with the respective $95 \%$ confidence intervals $(\mathrm{Cl})$. The significance level was set at $P<0.05$. Data were analyzed using the Statistical Package for the Social Sciences for Windows, version 13.0 (SPSS for Windows 13).

\section{Ethical permission}

Participants were thoroughly informed about the study and what was expected of them (in writing/verbally), and 
Table 1. Means, medians and means' 95\% confidence intervals of somatic symptoms (sub-scales and total) by education levels

\begin{tabular}{|c|c|c|c|c|c|c|}
\hline & $\begin{array}{l}\mathrm{m} / \mathrm{M}_{\mathrm{e}}(\mathbf{9 5 \%} \\
\text { Total } \\
\mathrm{N}=\mathbf{4 3 9 0}\end{array}$ & $\begin{array}{l}\text { Less than primary } \\
\mathrm{n}=661\end{array}$ & $\begin{array}{l}\text { Primary } \\
n=1092\end{array}$ & $\begin{array}{l}\text { Secondary } \\
\mathrm{n}=1782\end{array}$ & $\begin{array}{l}\text { University } \\
\mathrm{n}=855\end{array}$ & P-values $^{\mathbf{a}}$ \\
\hline Exhaustion & \begin{tabular}{|l}
$4.9 / 3$ \\
$(4.8-5.1)$
\end{tabular} & $\begin{array}{l}7.1 / 6 \\
(6.6-7.6)\end{array}$ & $\begin{array}{l}5.7 / 4 \\
(5.4-6.1)\end{array}$ & $\begin{array}{l}4.2 / 2 \\
(4.0-4.5)\end{array}$ & $\begin{array}{l}3.6 / 2 \\
(3.3-4.0)\end{array}$ & $p<0.0001$ \\
\hline Gastrointestinal & $\begin{array}{l}2.1 / 1 \\
(2.0-2.2)\end{array}$ & $\begin{array}{l}2.9 / 1 \\
(2.6-3.3)\end{array}$ & $\begin{array}{l}2.3 / 1 \\
(2.1-2.5)\end{array}$ & $\begin{array}{l}2.0 / 1 \\
(1.8-2.1)\end{array}$ & $\begin{array}{l}1.4 / 0 \\
(1.3-1.6)\end{array}$ & $p<0.0001$ \\
\hline Cardiovascular & $\begin{array}{l}2.7 / 1 \\
(2.6-2.8)\end{array}$ & $\begin{array}{l}3.9 / 2 \\
(3.5-4.2)\end{array}$ & $\begin{array}{l}3.1 / 2 \\
(2.9-3.3)\end{array}$ & $\begin{array}{l}2.5 / 1 \\
(2.3-2.6)\end{array}$ & $\begin{array}{l}1.8 / 1 \\
(1.6-2.0)\end{array}$ & $p<0.0001$ \\
\hline Musculoskeletal & $\begin{array}{l}6.6 / 5 \\
(6.4-6.7)\end{array}$ & $\begin{array}{l}9.8 / 9 \\
(9.3-10.3)\end{array}$ & $\begin{array}{l}7.3 / 6 \\
(6.9-7.6)\end{array}$ & $\begin{array}{l}5.9 / 5 \\
(5.7-6.1)\end{array}$ & $\begin{array}{l}4.7 / 3 \\
(4.4-4.9)\end{array}$ & $p<0.0001$ \\
\hline Total GBB-24 & $\begin{array}{l}16.3 / 12 \\
(15.8-16.7)\end{array}$ & $\begin{array}{l}23.7 / 20 \\
(22.3-25.1)\end{array}$ & $\begin{array}{l}18.4 / 15 \\
(17.5-19.3)\end{array}$ & $\begin{array}{l}14.6 / 11 \\
(13.9-15.2)\end{array}$ & $\begin{array}{l}11.6 / 8 \\
(10.8-12.3)\end{array}$ & $p<0.0001$ \\
\hline
\end{tabular}

m-mean and its standard deviation; Me - median; $\mathrm{Cl}$ - confidence interval; $n$ - number of observed persons; ${ }^{a-K r u s k a l l-W a l l i s ~ t e s t ~}$

informed consent was requested. Emphasis was put on confidentiality, anonymity and the participant's rights. The ethical application was similar, but customized for each country. Ethical permission was sought and received prior to data collection in each country, except for Greece where ethical permission was not necessary. However, Greece followed the same ethical principles as the other countries as well as the codes and guidelines of the QED and ICC/ESOMAR. *

\section{Results}

\subsection{Descriptive and bivariate analyses}

Of the 4467 respondents, 1,908 (42.5\%) were males and $2,559(57.5 \%)$ females. The distribution of respondents by age was: $60-64$ years $(25.2 \%), 65-69$ years $(24.4 \%), 70-74$ years $(21.1 \%), 75-79$ years $(16.1 \%)$ and 80-84 years (12.2\%); by education: cannot read/write $(3.1 \%)$, without any degree $(4.2 \%)$, less than primary school $(7.5 \%)$, primary school/similar $(24.4 \%)$, secondary school/similar $(40.0 \%)$, university/similar $(19.2 \%)$, and other (1.6\%).

As shown in Table 1, the mean scores in total GBB scale and subscales (exhaustion, gastrointestinal,

Respondents were informed before and at the start of the interview, and could stop participation at any time even during the interview. Self-responders were also informed before and if they changed their mind they did not need to send back the questionnaire. The ethical permissions were given by: Germany, Ethikkommission des Landes BadenWuerttenberg; Italy, Bioethics Advisory Committee of National Institute of Health and Science on Aging, INRCA; Lithuania, The Lithuanian State Data Protection Inspectorate and the Kaunas Regional Bioethics Committee; Portugal, Comité de Ética do Hospital de João; Spain, Comité de Etica en Investigación de la Universidad de Granada; Sweden, Regional Ethical Committee at Karolinska Institutet. Greece, The QED conducted the field work under the codes and guidelines of ICC/ESOMAR which are similar to ethical provisions in the other participating countries. cardiovascular, and musculoskeletal) were lowest among respondents with university degree.

As shown in Table 2, the most prevalent complaints were pain in joints and limbs $(29.6 \%)$, back-pain $(24.1 \%)$, heaviness or tiredness in the legs $(19.1 \%)$ and general tiredness (15.7\%). In addition, there was a significant difference in the prevalence of complaints between educational level groups, i.e. less educated persons complained more of somatic symptoms than ones that were more educated.

\subsection{Multivariate analyses}

As shown in Table 3, higher education was associated with decreased level of somatic symptoms (total and sub-scales) (OR from 0.75 to 0.85). In addition, being male was associated with reporting less total somatic complaints (OR varied from 0.40 to 0.78 ). While opposite effect was observed with older age. Statistically significant OR were measured for total somatic complaints $(O R=1.03)$ and the sub-scales exhaustion $(O R=1.04)$, cardiovascular $(\mathrm{OR}=1.03)$ and musculoskeletal $(\mathrm{OR}=1.03)$ complaints. Similar tendencies were indentified with marital status. Being single/divorced/window increased "risk" of reporting more somatic symptoms (total and sub-scales), except for the musculoskeletal complaints sub-scale.

\section{Discussion}

Somatic complaints are common in the general population. For example, a study from Nordic countries reported that more than $75 \%$ of the respondents had had one or more subjective health complaints in the past 30 days [12]. More than $50 \%$ reported tiredness, $42 \%$ headache, $37 \%$ worries, $35 \%$ low back pain, and $33 \%$ 
Table 2. Somatic complaints by item and education level

\begin{tabular}{|c|c|c|c|c|c|c|}
\hline & $\begin{array}{l}\text { Total } \\
\text { (\%) } \\
\mathbf{N}=\mathbf{4 3 9 0}\end{array}$ & $\begin{array}{l}\text { Less than } \\
\text { primary } \\
(\%)\end{array}$ & $\begin{array}{l}\text { Primary } \\
(\%) \\
n=1092\end{array}$ & $\begin{array}{l}\text { Secon- } \\
\text { dary } \\
(\%)\end{array}$ & $\begin{array}{l}\text { Univer-sity } \\
(\%) \\
n=855\end{array}$ & P-values ${ }^{a}$ \\
\hline & & $\mathrm{n}=661$ & & $n=1782$ & & \\
\hline Physical weakness & 14.3 & 27.8 & 18.0 & 10.3 & 7.6 & $\mathrm{P}<0.001$ \\
\hline Heavy, rapid or irregular heart-throbbing & 10.1 & 14.7 & 12.6 & 9.0 & 5.5 & $P<0.001$ \\
\hline Pressure or heaviness in the stomach & 5.5 & 10.4 & 6.1 & 5.0 & 2.1 & $P<0.001$ \\
\hline Excessive need for sleep & 6.7 & 8.9 & 8.0 & 5.8 & 5.1 & $\mathrm{P}<0.01$ \\
\hline Pains in joints or limbs & 29.6 & 51.1 & 32.7 & 25.6 & 17.4 & $\mathrm{P}<0.001$ \\
\hline Dizziness & 7.9 & 14.8 & 9.6 & 6.1 & 4.0 & $\mathrm{P}<0.001$ \\
\hline Backache & 24.1 & 44.0 & 25.5 & 21.0 & 13.5 & $\mathrm{P}<0.001$ \\
\hline Pains in neck or shoulders & 21.5 & 43.3 & 24.1 & 16.6 & 11.5 & $\mathrm{P}<0.001$ \\
\hline Vomiting & 1.6 & 3.0 & 2.9 & 0.8 & 0.5 & $\mathrm{P}<0.001$ \\
\hline Nausea & 2.0 & 4.7 & 2.7 & 1.2 & 0.6 & $\mathrm{P}<0.001$ \\
\hline $\begin{array}{l}\text { Sensation of tightness, choking or } \\
\text { lumpiness in the throat }\end{array}$ & 4.0 & 9.5 & 4.4 & 2.9 & 1.4 & $P<0.001$ \\
\hline Belching & 3.8 & 8.0 & 4.7 & 2.7 & 1.5 & $P<0.001$ \\
\hline Heartburn & 5.4 & 9.1 & 5.9 & 5.2 & 2.3 & $\mathrm{P}<0.001$ \\
\hline Headaches & 9.0 & 20.7 & 10.8 & 5.4 & 4.8 & $P<0.001$ \\
\hline Tendency to rapid exhaustion & 14.2 & 28.0 & 17.4 & 10.4 & 7.5 & $\mathrm{P}<0.001$ \\
\hline Tiredness & 15.7 & 32.5 & 17.8 & 11.3 & 9.1 & $\mathrm{P}<0.001$ \\
\hline Feeling numb or benumbed & 9.3 & 18.0 & 10.6 & 7.5 & 4.7 & $\mathrm{P}<0.001$ \\
\hline Heaviness or tiredness in the legs & 19.1 & 38.3 & 22.8 & 14.4 & 9.4 & $\mathrm{P}<0.001$ \\
\hline Weariness & 10.2 & 20.3 & 13.3 & 7.2 & 4.8 & $\mathrm{P}<0.001$ \\
\hline Twinges, pains or aching in the chest & 4.0 & 7.9 & 4.9 & 3.0 & 1.9 & $P<0.001$ \\
\hline Stomach-aches & 4.4 & 7.7 & 5.0 & 3.8 & 2.5 & $\mathrm{P}<0.001$ \\
\hline Attacks of breathlessness & 3.8 & 7.6 & 4.5 & 2.9 & 1.9 & $P<0.001$ \\
\hline Head-pressure & 5.5 & 11.6 & 7.2 & 3.6 & 2.2 & $P<0.001$ \\
\hline Sudden bouts of heart-trouble & 5.6 & 9.7 & 5.8 & 5.5 & 2.2 & $P<0.001$ \\
\hline
\end{tabular}

$n$ - number of observed persons; ${ }^{a}$ - Chi-square test

pain in their arms and shoulders. Studies with the GBB24 scale indicate that somatic complaints are very common in the general population and the levels vary from 17.7 (for all age groups) to 21.3 (61-70 years) and 25.9 (>70 years) $[6,13]$. A growing number of studies reports an increase in complaints with age, i.e. elders express more health complaints than younger $[4,8,14]$. However, the relation between older age and increased levels of somatic complaints is not consistent across all studies. Some researchers emphasize that older persons evaluate their health status more positively, even sometimes better than younger [15]. An explanation could be that elders compared to younger have a long experience in dealing with live events and thus are able to cope better with diseases, or elders may consider diseases as more a normative age-related change than a health problem 
Table 3. Logistic regression analysis of the relation between high levels of somatic symptoms (sub-scales and total), education, age and marital status.

\begin{tabular}{|c|c|c|c|c|}
\hline Somatic complaints & $\begin{array}{l}\text { Variables (OR, 95\% } \\
\text { Higher education }\end{array}$ & Being male & Older age & $\begin{array}{l}\text { Being single / } \\
\text { divorced/ windowed }\end{array}$ \\
\hline $\begin{array}{l}\text { Exhaustion sub-scale } \\
(\mathrm{Me}=3)\end{array}$ & $\begin{array}{l}0.75 \\
(0.70-0.80)\end{array}$ & $\begin{array}{l}0.61 \\
(0.53-0.69)\end{array}$ & $\begin{array}{l}1.04 \\
(1.03-1.05)\end{array}$ & $\begin{array}{l}1.31 \\
(1.14-1.50)\end{array}$ \\
\hline Gastrointestinal sub-scale $(\mathrm{Me}=1)$ & $\begin{array}{l}0.85 \\
(0.79-0.90)\end{array}$ & $\begin{array}{l}0.78 \\
(0.68-0.89)\end{array}$ & $\begin{array}{l}1.00 \\
(0.99-1.01)\end{array}$ & $\begin{array}{l}1.23 \\
(1.07-1.40)\end{array}$ \\
\hline Cardiovascular sub-scale $(\mathrm{Me}=1)$ & $\begin{array}{l}0.80 \\
(0.75-0.85)\end{array}$ & $\begin{array}{l}0.58 \\
(0.51-0.66)\end{array}$ & $\begin{array}{l}1.03 \\
(1.02-1.04)\end{array}$ & $\begin{array}{l}1.23 \\
(1.07-1.40)\end{array}$ \\
\hline Musculoskeletal sub-scale $(\mathrm{Me}=5)$ & $\begin{array}{l}0.68 \\
(0.64-0.73)\end{array}$ & $\begin{array}{l}0.40 \\
(0.35-0.46)\end{array}$ & $\begin{array}{l}1.03 \\
(1.02-1.04)\end{array}$ & $\begin{array}{l}1.10 \\
(0.96-1.26)\end{array}$ \\
\hline Total GBB-24 scale $(\mathrm{Me}=12)$ & $\begin{array}{l}0.69 \\
(0.64-0.74)\end{array}$ & $\begin{array}{l}0.48 \\
(0.42-0.55)\end{array}$ & $\begin{array}{l}1.03 \\
(1.02-1.04)\end{array}$ & $\begin{array}{l}1.28 \\
(1.11-1.47)\end{array}$ \\
\hline
\end{tabular}

OR - odds ratio; Cl - confidence interval; Me-median

$[16,17]$. However, some studies emphasize that discrepancy exists between subjective and objective health in the old age [18]. This indicating that self-perceived health and self-reported somatic complaints in older persons should be evaluated reservedly.

The findings from ABUEL study indicate that respondents with higher education reported less somatic complaints than less educated participants. This in line with other studies, showing that a higher level of education is related with a better health status [19-21]. However, some large-scale multinational studies revealed that health effects of education are stronger at ages 25-55 than in the older age groups [22], indicating that the importance of education reduces in older age. Murrell \& Meeks [23] have tried to explain the link "education - health" in old age by analyzing the role of potential mediators. They considered three types of possible mediators: economic, psychological, and social.

It $t$ is common to emphasize the positive effect of education on higher incomes in older persons and better financial accessibility to health care services [24-26]. However, it may not be an explanation for every country. For instance, Lithuania has reported high inequalities by education, but this gap among elders can hardly be explained in economical terms [20]. Present Lithuanian elders have lived most of their lives under the communist regime. In that system, the higher education did not guarantee higher incomes or more respect in society. On the contrary, skilled "blue-collar" workers were more valued than "white-collar" ones. This indicates that economic factors may not be suitable for explaining educational inequalities in some societies.

A number of studies emphasize the importance of social and psychological factors in explaining the association between education and health. Factors such as life satisfaction, low-risk occupations and better social relationships are factors, which ensure better health status in the latter life $[27,28]$. These findings support the theory of cumulative advantage. According to it, educational attainment increases the resources that cumulate through life, producing a larger gap in the elderly [29].

The above-mentioned theory and our findings suggest that education itself can contribute to better health in the elderly. Therefore, the investment in education can lead to better public health and less intensive use of health care services in this segment of the population. However, there are some threats as well. Higher education and the development of information technologies offers greater opportunities for seeking information; allow making comparisons with health care procedures in other countries; making patient more active in the "patient-physician" interactions [30]. Thus, it could be that elders that are more educated will expect better quality and expensive health care services.

\section{Limitations}

This study has limitations. The samples (women/men) were recruited from urban centers in seven European countries and results might not be applicable to rural areas. Second, non-responders were not investigated. It could be that refusals had more somatic complaints than responders did. Third, the accuracy of the data was dependent on the participants' subjective assessment of their situation. No objective evaluations (e.g. hospital records) have been performed to corroborate their responses. Thus, in spite of these limitations, our data suggest for the first time a strong relationship between education and self reported health. 


\section{Conclusions}

This study may add to the growing evidence of associations between education and somatic complaints. The results indicate that somatic complaints are more common among participants from lower education groups contrasted to those with university degree. This indicates that social policy should be aimed at reducing inequalities in education by guaranteeing equal opportunities for education and promoting young people to complete their education. Constructive actions should be developed to address the health problems of the least privileged groups in terms of education. Among the many approaches to solve this problem, we would like to emphasize investment in human capital, creation of effective social support systems, and increase

\section{References}

[1] Eurostat. Proportion of population aged 65 and over. Available at: http://epp.eurostat.cec.eu.int/ portal. Accessed: 26 September 2010

[2] Kanopiene V., Mikulioniene S., Population ageing and its challenges to health care system, Gerontologija, 2000, 7, 188-200 (in Lithuanian)

[3] Idler E., Benjamin Y., Self-rated health and mortality: a review of twenty-seven community studies, J. Health. Soc. Behav., 1997, 38, 21-27

[4] Molarious A., Janson S., Self-rated health, chronic diseases and symptoms among middle-aged and elderly men and women, J. Clin. Epidemiol., 2000, 55, 364-370

[5] Eriksen H.R., Ihleaek C., Subjective health complaints, Scand. J. Psychol., 2002, 43, 101-103

[6] Beutel M.E., Weidner K., Schwarz R., Brahler E., Age-related complaints in women and their determinants based on a representative community study, Eur. J. Obstet. Gynecol. Reprod. Biol., 2004, 117, 204-212

[7] Borglin G., Jakobsson U., Edberg A.K., Hallberg I.R., Self-reported health complaints and their prediction of overall and health-related quality of life among elderly people, Int. J. Nurs. Stud., 2005, 42, 147-158

[8] Gunzelmann T., Hinz A., Brahler E., Subjective health in older people, Psychosoc. Med., 2006, 3, Doc02

[9] Tibblin G., Bengtsson C., Furunes B., Lapidus L., Symptoms by age and sex. The population studies of men and women in Gothenburg, Sweden, Scand. J. Prim. Health. Care., 1990, 8, 9-17 accessibility to health care and psychological help for the elderly. Only multi-sector collaboration and common efforts will be able to accept this public health challenge.

\section{Acknowledgments}

We would like to express their appreciation for the financial support by the European Union through the Executive Agency for Health and Consumers (EAHC), which made possible the realization of the project. We extend also our appreciation to the staff of EAHC, and in particular Dr. Guy Dargent, for their help. Furthermore, we would like to express their appreciation to all participating institutions and to the staff involved in ABUEL. Finally, most of all, all authors, appreciate the kindness, efforts and answers of the elderly who participated in ABUEL.

[10] Lindert J., Luna J., Torres-Gonzalez F., Barros H., Ioannidi- Kapolou E., Quattrini S. et. al., Study design, sampling and assessment methods of the European study "Abuse of the Elderly in the European Region”, Eur. J. Public. Health., 2012, 22, 662-666

[11] Brähler E., Scheer J.W., Der Giessener Beschwerdebogen GBB. Testhandbuch, Huber Verlag, Bern,1995 (in German)

[12] Eriksen H.R., Svendsrod R., Ursin G., Ursin H., Prevalence of subjective health complaints in the Nordic European countries in 1993, Eur. J. Public. Health., 1998, 8, 294-298

[13] Kirkcaldy B.D., Siefan R.G., Wittig U., Schuller A., Brahler E., Merbach M., Health and emigration: subjective evaluation of health status and physical symptoms in Russian - speaking migrants, Stress. Health., 2005, 21, 295-309

[14] Bressler H.B., Keyes W.J., Rochon P.A., Bradley E., The prevalence of low back pain in the elderly, Spine., 1999, 24, 1813-1819

[15] Zhao J., Barclay S., Farquhar M., Kinmonth A.L., Brayne C., Fleming J., The oldest old in the last year of life: population-based findings from Cambridge City over-75s cohort study participants aged 85 and older at death, J. Am. Geriatr. Soc., 2010, 58, 1-11

[16] Jang Y., Poon L.W., Martin P., Individual differences in the effects of disease and disability on depressive symptoms: the role of age and subjective health, Int. J. Aging. Hum. Dev., 2004, 59, 125-137 
[17] Martin P., Rott C., Poon L.W., Courtenay B., Lehr U., A molecular view of coping behavior in older adults, J. Aging. Health., 2001, 13, 72-91

[18] Lehr U., Gesundheit und Lebensqualitat im Alter, Z Gerontopsyhol., 1997,10, 277-87 (in German)

[19] Helasoja V., Lahelma E., Prattala R., Klumbiene J., Pudule I., Tekkel M., Trends in the magnitude of educational inequalities in Estonia, Latvia, Lithuania and Finland during 1994-2004, Public Health, 2006,120, 841-853

[20] Kalediene R., Starkuviene S., Petrauskiene J., Inequalities in life expectancy by education and socioeconomic transition in Lithuania, Medicina (Kaunas), 2008, 44, 713-722

[21] Mackenbach J.P., Stirbu I., Roskam A.J.R., Schaap M.M., Menvielle G., Leinsalu M., et al., Socioeconomic inequalities in health in 22 European Countries, N. Engl. J. Med. 2008, 358, 2468-2481

[22] Knesebeck O., Verde P.E., Dragano N., Education and health in 22 European countries, Soc. Sci. Med., 2006, 63, 1344-1351

[23] Murrell S.A., Meeks S., Psychological, economic, and social mediators of the education-health relationship in older adults, J. Aging. Health., 2002, 14, 527-550
[24] Avlund K., Davidsen M., Schroll M., Changes in functional ability from ages 70 to 75 , J. Aging. Health., 1995, 7, 254-282

[25] Morgan M., Marital status, health, illness, and service use, Soc. Sci. Med., 1980, 14A, 633-643

[26] Stankuniene A., Radziunas R., Stankunas M., Soares J.F., Baranauskas A., Ioannidi-Kapolou E. et al., Causes of refrain from buying prescribed medications among the elderly in Kaunas, Lithuania, Medicina (Kaunas), 2011, 47, 291-296

[27] Leonard W., Successful aging: An elaboration of social and psychological factors, Int. J. Aging. Hum. Dev., 1981-1982, 14, 223-232

[28] Girzadas P., Counte M., Glandon G., Tancredi D., An analysis of elderly health and life satisfaction, Behav. Health. Aging., 1993, 3, 103-117

[29] Dannefer D., Cumulative advantage / disadvantage and life course: cross-fertilizing age and social science theory, J. Gerontol., 2003, 58B, S327-337

[30] The future of health care and care for the elderly: guaranteeing accessibility, quality and financial viability. Communication from the Commission to the Council, the European Parliament, the Economic and Social Committee and the Committee of the Regions, COM (2001) 723 final, 05.12.2001 